\title{
A diet rich in phosphatidylethanolamine increases plasma homocysteine in mink: a comparison with a soyabean oil diet
}

\author{
Hanne Müller ${ }^{1 *}$, Terje Grande ${ }^{2}, \emptyset y s t e i n$ Ahlstrøm ${ }^{1}$ and Anders Skrede ${ }^{1,3}$ \\ ${ }^{1}$ Department of Animal and Aquacultural Sciences, Norwegian University of Life Sciences, PO Box 5003, N-1432 Å, Norway \\ ${ }^{2}$ University College of Akershus, PO Box 423, 2001 Lillestrøm, Norway \\ ${ }^{3}$ Aquaculture Protein Centre, Centre of Excellence, PO Box 5003, N-1432 As, Norway \\ (Received 19 November 2004 - Revised 25 May 2005 - Accepted 16 June 2005)
}

\begin{abstract}
The effects of high dietary levels of phosphatidylethanolamine (PE) on plasma concentrations of homocysteine (tHcy) have not previously been studied. Eighteen mink (Mustela vison) studied were fed one of three diets during a $25 \mathrm{~d}$ period in a parallel-group design. The compared diets had 0,17 and $67 \%$ extracted lipids from natural gas-utilising bacteria (LNGB), which were rich in PE. The group with $0 \%$ LNGB was fed a diet of $100 \%$ soyabean oil (SB diet). Phospholipids are the main lipid components in LNGB and Methylococcus capsulatus is the main bacteria (90\%). The fasting plasma concentration of tHcy was significantly higher when the mink consumed the diet with $67 \%$ LNGB than when they consumed the SB diet $(P=0 \cdot 039)$. A significantly lower glutathione peroxidase activity was observed in mink consuming the $17 \%$ LNGB diet or the $67 \%$ LNGB diet than was observed in mink fed the SB diet. The lack of significant differences in the level of plasma PE due to the diets indicates that most of the PE from the $67 \%$ LNGB diet was converted to phosphatidylcholine (PC) in the liver. It has previously been hypothesised that phosphatidylethanolamine N-methyltransferase is an important source of tHcy. The present results indicate that plasma tHcy is at least partly regulated by phospholipid methylation from PE to PC. This methylation reaction is a regulator of physiological importance.
\end{abstract}

Homocysteine: Phosphatidylethanolamine: Diet: Natural gas-utilising bacteria

Bacterial protein meal, produced by natural gas-utilising bacteria (Skrede et al. 1998) contains a high crude protein level (70\%) and also a high level of lipids (10\%) (Müller et al. 2004). Four different bacteria, Methylococcus capsulatus (Bath) (90\%), and to a minor degree Ralstonia sp., Brevibacillus agri and Aneurinibacillus sp., are grown using natural gas (99\% methane), ammonia and mineral salts as fermentation substrates (Skrede et al. 1998). Phospholipids are the main lipid components in M. capsulatus. Phosphatidylethanolamine (PE) constitutes $74 \%$ of the total phospholipids of $M$. capsulatus, with phosphatidylglycerol (13\%), phosphatidylcholine (PC) $(8 \%)$ and cardiolipin $(5 \%)$ (Makula, 1978).

Homocysteine (tHcy) is a non-protein sulfhydryl-containing amino acid in normal human plasma (Mudd et al. 2000). It is derived from the catabolism of S-adenosylhomocysteine (SAH), an immediate product of trans-methylation reactions with S-adenosylmethionine (SAM) as methyl donor (Yi et al. 2000). Hepatocytes synthesise PC through the PE methylation pathway and also through the cytidine diphosphat-choline pathway (Tijburg et al. 1989; DeLong et al. 2002).

There is a relationship between the conversion of PE to PC via the PE methyltransferase (PEMT) pathway and the formation of tHcy in the liver (Noga et al. 2003). Interestingly, the study by Noga et al. (2003) showed that mice lacking PEMT activity have plasma levels of tHcy that are about $50 \%$ of those in wild-type mice, indicating that the PEMT reaction or phospholipid methylation in the liver is a major source of plasma tHcy. They used a PEMT knock-out mouse and not native animals and concluded that the flux through the enzyme is a positive predictor of plasma tHcy (Noga et al. 2003).

tHcy derived from methionine metabolism is a modified form of methionine and is significantly re-methylated into methionine to conserve sufficient methionine for protein and SAM synthesis. Up to $48 \%$ of methionine is converted to $6-8 \mathrm{~g} \mathrm{SAM}$ in the human liver daily (Yi et al. 2000). SAM plays a role as a methyl donor for hundreds of cellular methylation reactions and most cellular methyltransferase reactions (Finkelstein, 1990; Chiang et al. 1996), including the stepwise methylation of PE to PC (Tijburg et al. 1989). Recently, DeLong et al. (2002) showed that choline also acts as a methyl group donator for PE methylation in hepatocarcinoma cells. In the liver, SAM (Ridgway et al. 1989; Tijburg et al. 1989) and to a minor degree choline (DeLong et al. 2002) are methyl donors in the synthesis of PC from PE by stepwise 3 transmethylation reactions of PE by PEMT.

Previously, we have shown that replacing soyabean oil diets with diets containing high levels of extracted lipids from natural gas-utilising bacteria (LNGB), rich in PE, reduces plasma lipoproteins in mink (Müller et al. 2004). To our knowledge, no

Abbreviations: GPx, gluthatione peroxidase; HPTLC, high-performance TLC; LNGB, lipids from natural gas-utilising bacteria; 17LNGB diet, $83 \%$ soyabean oil and $17 \%$ extracted LNGB diet; 67LNGB diet, $33 \%$ soyabean oil and $67 \%$ extracted LNGB diet; lysoPC, lysophosphatidylcholine; PC, phosphatidylcholine; PE, phosphatidylethanolamine; PEMT, phosphatidylethanolamine methyltransferase; SAH, S-adenosylhomocysteine; SAM, S-adenosylmethionine; SB diet, $100 \%$ soyabean oil diet; THcy, homocysteine.

*Corresponding author: Dr Hanne Müller, fax +47 64965101, email hanne.muller@umb.no 
study has been published on the effects of high dietary levels of $\mathrm{PE}$ on plasma concentrations of tHcy. Our hypothesis would be that a high level of dietary PE will result in increased conversion of PE to PC, increased level of SAH and thus a rise in tHcy concentration compared with soyabean oil. The purpose of the present study was to study the effects of diets containing high levels of PE on plasma tHcy in mink compared with a soyabean oil diet. Because of considerations such as mink farming and evolutional adaptation to diets with a high lipid content, mink (Mustela vison) were used as experimental animals for other mammals, including man.

\section{Materials and methods}

\section{Lipids extracted from bacterial protein meal}

Bacterial protein meal (BioProtein), used for the lipid extraction, was produced by continuous aerobic fermentation using natural gas as the $\mathrm{C}$ and energy source, and ammonia as the $\mathrm{N}$ source for protein biosynthesis (Norferm AS, Stavanger, Norway) (Skrede et al. 1998). The bacteria culture consisted of prokaryote bacteria containing $90 \%$ M. capsulatus (Bath), with smaller amounts of Ralstonia sp., Brevibacillus agri and Aneurinibacillus sp. (Skrede et al. 1998). This biomass was subjected to a shorttime heat treatment at $140^{\circ} \mathrm{C}$ to obtain a sterile product of dead bacteria, which was then spray-dried to a reddish-brownish meal with about $96 \%$ DM (Skrede et al. 1998) and a particle size of $150-200 \mu \mathrm{m}$. The lipids from the biomass were extracted by chloroform-methanol (2:1, v/v) (Folch et al. 1957). After mixing with the bacterial protein meal, the solvent was tapped from the mixing tank to several filter bags with pore size $5 \mu \mathrm{m}$. The extraction was performed twice and the rest of the solvent was removed by mixing the lipids at reduced pressure and high temperature. The lipid extraction was performed at Natural ASA, Hovdebygda, Norway.

\section{Animals and diets}

Eighteen 5-6-month-old farm-bred mink (M. vison) males of genotype standard dark were randomised and fed one of three diets for a $25 \mathrm{~d}$ period in a parallel-group design at the Department of Animal and Aquacultural Sciences at the Norwegian University of Life Sciences. The study ran from October to November 2002. The body weight of the animals was monitored before the animals entered the experiment and at the end of the study period. The average initial weight of the mink was 2221 (SD 316) g. During a $7 \mathrm{~d}$ digestibility experiment, week 1 of the study, the animals were housed individually in net cages of sizes $(51 \times 39 \times 49 \mathrm{~cm})$ designed for metabolism experiments with devices to catch spilled feed and to minimise contamination of faeces with urine. The temperature was kept constant at $13^{\circ} \mathrm{C}$ and the daily light-dark cycle was controlled by photocells and adapted to a natural photoperiod. After the digestibility experiment, the mink were kept under conventional farm housing conditions in net cages $(75 \times 30.5 \times 38 \mathrm{~cm})$ equipped with wooden nest boxes $(35 \times 26 \times 22 \mathrm{~cm})$, to provide a secluded rest area for the remainder of the experimental period.

The three high-lipid diets were planned using a computer-based optimisation program and were designed to have the same nutrient composition (Table 1), with each diet containing adequate quantities of all nutrients known to be required by mink (National
Table 1. Composition of experimental diets $(\mathrm{g} / \mathrm{kg})$

\begin{tabular}{lccc}
\hline Diet & SB diet & 17LNGB diet & 67LNGB diet \\
\hline Maize starch & 62.9 & 62.9 & 62.9 \\
Coalfish fillet & 611.5 & 651.4 & 651.4 \\
Soyabean oil & 91.4 & 61.0 & 15.3 \\
Lipids from natural gas-utilising & - & 30.5 & 76.2 \\
$\quad$ bacteria & & & \\
Sunflower-seed oil & 2.29 & 2.29 & 2.29 \\
Vitamin and mineral mix & 0.84 & 0.84 & 0.84 \\
BHT (100 mg/kg) & 0.08 & 0.08 & 0.08 \\
Calcium phosphate & 1.63 & 1.63 & 1.63 \\
Calcium carbonate & 1.85 & 1.85 & 1.85 \\
Water & 227.5 & 187.7 & 187.7 \\
Gross energy (kJ/g dry & 24.53 & 25.43 & 22.69 \\
$\quad$ weight) $\dagger$ & & & 235.1 \\
Total feed intake (g/d) & 241.9 & 249.0 & \\
\hline
\end{tabular}

SB diet, $100 \%$ soyabean oil diet; 17LNGB diet, $83 \%$ soyabean oil and $17 \%$ extracted LNGB diet; 67 LNGB diet, $33 \%$ soyabean oil and $67 \%$ extracted LNGB diet; BHT, butylated hydroxytoluene.

*Contains (per kg diet): vitamin A, $504 \mu \mathrm{g}$; vitamin $\mathrm{D}_{3}, 4.2 \mu \mathrm{g}$; vitamin E, $42 \mathrm{mg}$; thiamin, $12.6 \mathrm{mg}$; riboflavin, $2.5 \mathrm{mg}$; vitamin $\mathrm{B}_{6}, 2.5 \mathrm{mg}$; vitamin $\mathrm{B}_{12}, 17 \mu \mathrm{g}$; pantothenic acid, $2.5 \mathrm{mg}$; niacin, $4.2 \mathrm{mg}$; biotin, $25 \mu \mathrm{g}$; folate, $0.25 \mathrm{mg}$; Fe, $17 \mathrm{mg}$; Zn, $6 \mathrm{mg}$; Mn, $12.6 \mathrm{mg}$; $\mathrm{Cu}, 1 \mathrm{mg}$ (AS Norsk Mineralnæring, Hønefoss, Norway). † Determined on freeze-dried samples by bomb calorimeter.

Research Council, 1982). Each diet had $29.7 \%$ energy derived from protein and $14.5 \%$ from carbohydrates. The three tested diets differed in their amounts of triacylglycerols, phospholipids and individual fatty acids. The lipids from the background diets were planned to provide a small amount of $1.14 \%$ energy from lipids, whereas the test lipids were planned to provide $54.6 \%$ energy in the diets. Two different test lipids were used in the three diets: soyabean oil (in the control diet) and extracted lipids from BioProtein. The three high-lipid diets contained the following added lipids: (1) $100 \%$ soyabean oil (SB diet); (2) $83 \%$ soyabean oil and $17 \%$ extracted LNGB (17LNGB diet); and $33 \%$ soyabean oil and $67 \%$ extracted LNGB (67LNGB diet). The lipids from BioProtein, being solid at room temperature, were mixed with the soyabean oil and heated before mixing with the other ingredients.

\section{Experimental design}

All the mink consumed one of the three diets for $25 \mathrm{~d}$. During week 1 , the mink were individually fed rations providing $1100 \mathrm{~kJ}$ of metabolisable energy/animal per $\mathrm{d}$. Thereafter, the mink were fed ad libitum three times per $\mathrm{d}$ for the rest of the feeding period. Water was available ad libitum. The diets were stored at $-20^{\circ} \mathrm{C}$ and thawed in a refrigerator for $24 \mathrm{~h}$ before feeding. Faeces were stored at $-20^{\circ} \mathrm{C}$ and the diets and the faeces were freeze-dried before analyses. Animal care was in accordance with guidelines given by the Norwegian Animal Research Authority. National protocols of ethical standards concerning experiments involving animals were followed regarding animal care and method of killing by electrocution at the end of the experiment.

\section{Bomb calorimetry}

The duplicate portions of the three freeze-dried homogenates corresponding to an estimated intake of $1100 \mathrm{~kJ}$ were analysed by a PARR 1281 bomb calorimeter (PARR Instrument Company, Moline, IL, USA). 


\section{Chemical analysis of diets}

Duplicate samples were taken of the three diets and kept frozen at $-20^{\circ} \mathrm{C}$, freeze-dried and homogenised. The $\mathrm{N}$ content was determined by the Kjeldahl technique. The factor used for conversion of $\mathrm{N}$ content to crude protein was $6 \cdot 25$. Starch content (including free glucose) was determined as glucose after hydrolysis by $\alpha$ amylase and amylo-glucosidase as described by McCleary et al. (1994). The content of total fat was determined gravimetrically after Bligh and Dyer extraction (Bligh \& Dyer, 1959). The lipid phase was slowly evaporated under $\mathrm{N}_{2}$ (Hydro Gas, Oslo, Norway) and the lipids were redissolved in $1 \mathrm{ml}$ benzene (Merck KGaA, Darmstadt, Germany).

\section{Phospholipid analysis}

The extracted phospholipids from diets and plasma were analysed by quantitative high-performance TLC (HPTLC) using a solvent system consisting of chloroform-methanol-acetic acid-formic acid- ${ }^{2} \mathrm{H}_{2} \mathrm{O}$ (70:30:12:4:2, by vol.), and densitometric quantification, as previously described (Müller et al. 2004). Just before the analyses, the samples were dried under $\mathrm{N}_{2}$ and redissolved in a defined volume of chloroform-methanol (2:1, v:v). Samples and a quantitative standard mixture (a six-point standard curve ranging from 160 to $2500 \mathrm{ng}$ per plate) were applied on prewashed and activated silica HPTLC plates (Silica Gel -60; Merck GmbH, Darmstadt, Germany) using a DESAGA AS-30 HPTLC applicator (Desaga $\mathrm{GmbH}$, Wiesloch, Germany). The standard mixture in the analysis of plasma phospholipids contained egg yolk sphingomyelin, dioleoyl-PC, dioleoyl-phosphatidylinositol, dioleoyl-PS and dioleoyl-PE (Avanti Polar Lipids, Alabaster, AL, USA). For the analysis of phospholipids in the diet, dioleoyl-PC, dioleoyl-phosphatidylinositol, dioleoyl-PS, dioleoyl-PE, dioleoyl- phosphatidylglycerol, and cardiolipin from Escherichia coli (Avanti Polar Lipids, Alabaster, AL, USA) were used. In the analysis of phospholipids, the HPTLC plates were developed in chloroform-methanol-acetic acid-formic acid $-{ }^{2} \mathrm{H}_{2} \mathrm{O}$ (70:30:12:4:2, by vol.), and in the analysis of dietary phospholipids, development was carried out in three consecutive runs in methylacetate- $n$-propanol-chloroform-methanol-aqueous $0.25 \% \mathrm{KCl}$ (25:25:28:10:7, by vol.), increasing the length of the development by $2 \mathrm{~cm}$ for each run. Development was performed in a CAMAG Horizontal TLC-chamber (CAMAG, Muttenz, Switzerland). Following development, the plates were soaked with charring reagent $\left(633 \mathrm{mM}^{-\mathrm{CuSO}_{4}} \times 5 \mathrm{H}_{2} \mathrm{O}\right.$ in $8 \%$ phosphoric acid (Sigma, St Louis, MO, USA) and heated at $160^{\circ} \mathrm{C}$ for $6 \mathrm{~min}$. Quantification was performed through densitometry at $420 \mathrm{~nm}$, using a DESAGA CD-60 HPTLC densitometer (Desaga $\mathrm{GmbH}$ ) in reflectance mode. $R^{2}$ values for the regression line were never below 0.991 and inter-assay variability was $8 \%$ and intra-assay variability was $5 \%$. All standards used were of $99 \%$ purity or higher.

\section{Blood sampling and analyses}

Blood samples were taken in sodium-heparin vacuum tubes after an overnight fast at the end of the period immediately after electrocution and immediately chilled on ice. Plasma was obtained by low-speed centrifugation for $15 \mathrm{~min}$ at $3000 \mathrm{~g}$ within $15 \mathrm{~min}$ of heart puncture and the plasma was quickly separated and pipetted into plastic vials and stored at $-80^{\circ} \mathrm{C}$ until analysed.
Fasting plasma tHcy was determined using the Bio-Rad Thcy by HPLC test (catalogue no. 195-4075; Bio-Rad Laboratories $\mathrm{GmbH}$, Munich, Germany).

The modified coupled enzymic assay of plasma glutathione peroxidase (GPx) described by Paglia \& Valentine (1967) was applied. Phosphate buffer $(26 \mathrm{ml}), \mathrm{GSH}$, NADPH, glutathione reductase and sodium azide were mixed. Blanks lacking GPx were used. Then cumene hydroperoxide was added to initiate the reaction. The automated analyser equipment (Cobas Mira; Hoffman-La Roche \& Co., Basel, Switzerland) was used at the absorbance level of $340 \mathrm{~nm}$. The activity of GPx was defined as $\mathrm{IU}=1 \mathrm{nmol} \mathrm{NADPH}$ oxidised per min.

\section{Statistical methods}

Data were analysed by one-way ANOVA. The variables plasma tHcy and GPx were natural log-transformed before analysis. $P$ values $<0.05$ were considered significant. The Bonferroni method was used for a pair-wise comparison between the three diet groups and for calculation of $95 \%$ confidence limits for the differences between the diets. The Bonferroni method encompasses a downward adjustment of significance limits for the differences between the diets. All $P$ values are two-tailed. Correlation coefficients (Pearson) between levels of plasma tHcy and phospholipids are presented when suitable.

The statistical package SPSS 11.0 (SPSS Inc., Chicago, IL, USA) was used for the data analysis.

\section{Results}

The gross energy level was slightly lower in the 67LNGB diet than in the two other diets (Table 1). The feed intake (Table 1) and the final body mass did not differ significantly among the three groups.

The LNGB diets had a higher content of phospholipids than did the SB diet, and PE constituted a substantially higher percentage of the total phospholipids in the LNGB diets than in the SB diet (Table 2). The fasting plasma concentration of tHcy was significantly higher when the mink consumed a diet with $67 \%$ LNGB compared with the SB diet $(P=0.039)$ (Table 3). There were no significant differences in the level of plasma tHcy when the 17LNGB diet was compared with the SB diet (Table 3). Plasma total phospholipids, PC, lysophosphatidylcholine (lysoPC) and phosphatidylinositol were significantly lower for the mink fed the 67LNGB diet than for the mink fed solely soyabean oil (Table 3). The highest percentage decrease among the phospholipid classes when comparing the 67LNGB diet and the SB diet was observed in lysoPC and PC. No significant differences in the concentration of plasma $\mathrm{PE}$ were found among the diets (Table 3). However, PE constituted a significantly higher proportion of the total phospholipids, and the PE:PC ratio in plasma (Table 3 ) increased significantly for the animals that consumed the 67LNGB diet compared with those fed the SB diet.

Plasma tHcy was negatively correlated with PC $(r-0.74$; $P<0.001)$ but not with PE $(r-0.022 ; P=0.935)$. The PE:PC ratio was not significantly correlated with plasma tHcy ( $r$ 0.474; $P=0.063)$. There was a significant negative correlation between plasma tHcy and total phospholipids $(r-0.717 ; P<0.002)$. Faecal excretion of PC, lysoPC and PE (Table 4) was higher in the mink fed the 67LNGB diet than in those fed the SB diet, 
Table 2. Phospholipid content of the diets $(\mathrm{mg} / \mathrm{g})$

(Mean values and standard deviations)

\begin{tabular}{|c|c|c|c|c|c|c|c|c|c|}
\hline \multirow[b]{2}{*}{ Diet } & \multicolumn{3}{|c|}{ SB diet } & \multicolumn{3}{|c|}{ 17LNGB diet } & \multicolumn{3}{|c|}{ 67LNGB diet } \\
\hline & Mean & SD & $\%$ of total phospholipids & Mean & SD & $\%$ of total phospholipids & Mean & SD & $\%$ of total phospholipids \\
\hline $\mathrm{PC}$ & 3.3 & 0.3 & 74 & $10 \cdot 6$ & 0.8 & 60 & $25 \cdot 7$ & $2 \cdot 1$ & 44 \\
\hline Phosphatidylinositol & 0.4 & 0.0 & 9 & 0.7 & 0.1 & 4 & 1.8 & 0.2 & 3 \\
\hline $\mathrm{PE}$ & 0.04 & 0.0 & 1 & $2 \cdot 6$ & 0.3 & 15 & $19 \cdot 3$ & $2 \cdot 3$ & 33 \\
\hline Phosphatidylglycerol & 0.7 & 0.1 & 17 & $3 \cdot 3$ & 0.3 & 19 & $8 \cdot 8$ & 1.0 & 15 \\
\hline Cardiolipin & Traces & & & 0.4 & 0.0 & 2 & $2 \cdot 9$ & 0.2 & 5 \\
\hline
\end{tabular}

SB diet, $100 \%$ soyabean oil diet; 17 LNGB diet, $83 \%$ soyabean oil and $17 \%$ extracted LNGB diet; 67 LNGB diet, $33 \%$ soyabean oil and $67 \%$ extracted LNGB diet; PC, phosphatidylcholine; $\mathrm{PE}$, phosphatidylethanolamine.

and significantly higher in mink fed the 67LNGB diet than in animals fed the 17LNGB diet.

GPx activity was significantly lower in mink consuming the 17LNGB diet and the 67LNGB diet compared with the SB diet $(P<0 \cdot 01)$.

\section{Discussion}

The most important finding of the present study was that the fasting plasma concentration of tHcy was significantly higher for mink that had consumed the 67LNGB diet, rich in PE, than those that had consumed solely soyabean oil. Phospholipids are the main lipid components in natural gas-utilising bacteria and the lipids in the 67LNGB diet consisted mainly of PC and PE, but also of phosphatidylglycerol, cardiolipin and phosphatidylinositol.

The PE methylation pathway in tHcy metabolism is of special interest. There is a relationship between the synthesis of PC from $\mathrm{PE}$ in the liver and the formation of tHcy (Noga et al. 2003). SAM participates as a methyl donor in the synthesis of PC from PE in the hepatocytes. Thus, SAM is converted to SAH and further to tHcy. For each PC molecule synthesised, three $\mathrm{SAH}$ molecules are generated in the PEMT pathway as shown in Equation 1.

$$
\mathrm{PE}+3 \mathrm{SAM} \rightarrow \mathrm{PC}+3 \mathrm{SAH}
$$

Dietary PE results in PE methylation via PEMT to PC in the liver (Tijburg et al. 1989). High level of dietary PE is possibly of greatest importance in this reaction. The reaction may lead to an increased formation of PC (Equation 1) but higher excretion of $\mathrm{PC}$ in faeces, resulting in a lower level of plasma PC. Previous studies have shown that PC biosynthesis via the PE methylation pathway gave a raised biliary excretion of phospholipids in faeces (Noga \& Vance, 2003; Sehayek et al. 2003). An excess of PE and increased excretion of PC in faeces may sustain the reaction (Equation 1). Ridgway et al. (1989) have shown that the in vitro activity of PEMT is regulated by PE levels. One study has shown that the PEMT reaction in the liver is a major source of plasma tHcy (Noga et al. 2003). However, the latter study used knock-out mice to study phospholipid methylation. Native mink, which we used in the present study, may be better than knock-out animals as models for mammals, including man.

The PEMT pathway is an important source for PC in the bile (Agellon et al. 1999). An increased biliary excretion of phospholipids from PC biosynthesis via the PE methylation pathway (Agellon et al. 2003; Noga \& Vance 2003; Sehayek et al. 1999) may at least partly explain the lowered plasma concentration of PC from the 67LNGB diet compared with the SB diet.

In addition to PE, the 17LNGB and 67LNGB diets also contained more PC than did the SB diet. Furthermore, the dietary choline intakes were substantially different for the different

Table 3. Plasma homocysteine, phospholipids ( $\mu \mathrm{g} / \mathrm{ml}$ ) (Müller et al. 2004) and glutathione peroxidase (U/l) levels at the end of the three dietary test periods 1

(Mean values and standard deviations)

\begin{tabular}{|c|c|c|c|c|c|c|}
\hline \multirow[b]{2}{*}{ Diet } & \multicolumn{2}{|c|}{ SB diet } & \multicolumn{2}{|c|}{ 17LNGB diet } & \multicolumn{2}{|c|}{ 67LNGB diet } \\
\hline & Mean & SD & Mean & SD & Mean & SD \\
\hline Homocysteine ( $\mu \mathrm{mol} / \mathrm{l})$ & 11.83 & $5 \cdot 2$ & $17 \cdot 60$ & $4 \cdot 0$ & $19 \cdot 30 \S$ & 4.6 \\
\hline Total phospholipids & 4200 & 1137 & 3722 & 558 & $2685 \dagger$ & $251 \cdot 0$ \\
\hline $\mathrm{PC}$ & 3475 & 1003 & 3072 & 506 & $2162 \dagger$ & 256 \\
\hline Lysophosphatidylcholine & 114 & 22 & 97 & 15 & $61^{*}$ & 31 \\
\hline Sphingomyelin & 393 & $109 \cdot 5$ & 337 & $49 \cdot 6$ & $280 \|$ & 10 \\
\hline Phosphatidylinositol & 141 & 31 & 124 & 21 & $99 \ddagger$ & 10 \\
\hline $\mathrm{PE}$ & 77 & 24 & 94 & 23 & 83 & 21 \\
\hline PE:PC ratio & 0.022 & 0.005 & 0.031 & 0.010 & $0.039 \S$ & 0.010 \\
\hline Glutathione peroxidase (U/I) & 16013 & 1638 & $10688 \dagger$ & 1429 & $10583^{\star}$ & 2170 \\
\hline
\end{tabular}

SB diet, $100 \%$ soyabean oil diet; 17 LNGB diet, $83 \%$ soyabean oil and $17 \%$ extracted LNGB diet; 67 LNGB diet, $33 \%$ soyabean oil and $67 \%$ extracted LNGB diet; PC, phosphatidylcholine; PE, phosphatidylethanolamine.

Mean values were significantly different from those for the $\mathrm{SB}$ diet: ${ }^{*} P<0.001, \dagger P<0.02, \ddagger P=0.03, \S P=0.039, \| P=0.062(P=0.021$ without Bonferroni adjustment).

I Adjustment for multiple comparisons by the Bonferroni method. 
Table 4. Faecal excretion of phospholipids ( $n$ 6) (Müller et al. 2004)‡

(Mean values and standard deviations)

\begin{tabular}{|c|c|c|c|c|c|c|}
\hline \multirow[b]{2}{*}{ Diet } & \multicolumn{2}{|c|}{ SB diet } & \multicolumn{2}{|c|}{ 17LNGB diet } & \multicolumn{2}{|c|}{ 67LNGB diet } \\
\hline & Mean & SD & Mean & SD & Mean & SD \\
\hline Phosphatidylcholine $(\mu \mathrm{g} / \mathrm{d})$ & 0.94 & $0 \cdot 18$ & $2 \cdot 06$ & 0.56 & $12.57^{\star} \dagger$ & 3.67 \\
\hline Lysophosphatidylcholine ( $\mu \mathrm{g} / \mathrm{d})$ & 0.28 & $0 \cdot 10$ & $1 \cdot 78$ & $0 \cdot 86$ & $16 \cdot 64^{\star} \dagger$ & $5 \cdot 86$ \\
\hline Phosphatidylethanolamine $(\mu \mathrm{g} / \mathrm{d})$ & 0.16 & 0.05 & 0.49 & 0.13 & $5 \cdot 38^{*} \dagger$ & 2.04 \\
\hline
\end{tabular}

SB diet, $100 \%$ soyabean oil diet; 17 LNGB diet, $83 \%$ soyabean oil and $17 \%$ extracted LNGB diet; 67 LNGB diet, $33 \%$ soyabean oil and $67 \%$ extracted LNGB diet.

${ }^{*}$ Mean values were significantly different from those for the SB diet $(P<0.001)$.

t Mean values were significantly different from those for the 17LNGB diet $(P<0.001)$.

$\ddagger$ Adjustment for multiple comparisons by the Bonferroni method.

diets. An increase in concentration of choline has been shown in human plasma after intake of lecithin (Wurtman et al. 1979; Buchman et al. 1992). It has been suggested that the liver converts $60 \%$ of free choline (tetramethylglycine) into betaine (trimethylglycine) (DeLong et al. 2002). Previous studies have also shown that choline can be converted to PC via the CDP-choline pathway (Houweling et al. 1997). It is possible that PC has no direct effect on tHcy, but affects it only indirectly via choline and betaine. Betaine doses in the range of dietary intake have been shown to lower tHcy (Steenge et al. 2003; Olthof \& Verhoef, 2005). Choline might have an opposite effect of PE on plasma tHcy concentrations and reduce the effects of the 67LNGB diet on tHcy. This may be one of the reasons why the difference in the levels of plasma tHcy between the 17LNGB diet and the 67LNG diet was less than the difference between the levels in the SB diet and the 17LNGB diet. The effect of LNGB diets on concentration of tHcy can thus possibly be underestimated. The highest percentage decrease among the phospholipid classes for mink fed the 67LNGB diet was observed in lysoPC and PC. The lack of significant differences in the level of plasma PE due to the diets indicates that most of the PE in LNGB had been converted to PC in the liver and some was excreted in faeces. The significant reduction in plasma PC and the increase in plasma tHcy resulted in a high negative correlation between these parameters. Possibly, there is a biological association between the plasma PE:PC ratio and tHcy. However, the PE:PC ratio was not significantly higher in animals fed the 67LNGB diet than those fed the SB diet $(P=0.063)$. The reason why this effect did not reach statistical significance in the present study may be related to lack of power. The change in PC content in plasma in the present study has the greatest influence on the PE:PC ratio.

The PE methylation pathway is catalysed by PEMT1 and PEMT2, which catalyse identical reactions but differ in structure and cellular localisation (Cui et al. 1993). Mammalian cell types other than hepatocytes produce only minor amounts of PC through the methylation pathway of PE (Kent \& Carman, 1999).

SAM and SAH are important metabolic indicators of cellular methylation status as substrates and products of essential cellular methyltransferase reactions (Yi et al. 2000). Ridgway et al. (1989) have suggested that PE concentrations, the SAM:SAH ratio and phosphorylation are factors involved in the regulation of PEMT. According to Noga et al. (2003), PC synthesis from PE consumes substantially more SAM than was previously believed. If tHcy metabolism is impaired, an increase in
SAH level and a decrease in the SAM:SAH ratio inhibit transmethylation reactions (Miller et al. 1994; Loehrer et al. 1996; Yi et al. 2000).

Studies indicate that actively drinking patients with alcoholism (Bleich et al. 2005), and individuals who consume more coffee than $500 \mathrm{ml} / \mathrm{d}$ (Panagiotakos et al. 2004), have increased levels of tHcy. Ethanol has been shown to produce a stimulatory action on PE biosynthesis after chronic ingestion (Carrasco et al. 1996). Dietary PE and intake of alcohol can possibly cause similar conversion of PE to PC and a subsequent increase in tHcy. Caffeine is only partly responsible for the tHcy-increasing effect of coffee (Verhoef et al. 2002) and the other reasons for the homocysteine-increasing effect of coffee are not entirely understood.

Our previous study (Müller et al. 2004) supported the hypothesis that phospholipid methylation from PE to PC partly regulates lipoprotein metabolism. We reported that feeding a high level of LNGB lipids instead of soyabean oil resulted in significantly lower levels of plasma total cholesterol, LDL- and HDL-cholesterol, lower plasma LDL:HDL-cholesterol ratio, and increased total cholesterol, PC and PE in faeces. It was concluded that the lowering effects of a specific mixture of phospholipids on plasma cholesterol were mainly caused by PE, and not the fatty acid composition. These and the present findings suggest that the methylation from PE to PC may be connected to the metabolism of lipoproteins and tHcy.

The significance of tHcy levels in mink is not known, and normal values have not been established. However, the values of plasma tHcy in mink seem to be somewhat higher than in man (Rossi et al. 1999). Plasma tHcy has been shown to have a circadian variation, although a small amplitude one (Martins et al. 2005). Therefore, fasting blood sampling was done to minimise the variation.

tHcy may be involved in a large number of mechanisms leading to vascular diseases. The mechanism by which tHcy damages the vessel walls may be multifactorial. One hypothesis is that tHcy may act as a pro-oxidant, leading to vascular diseases and decreased GPx activity (Selhub 1999). tHcy has been shown to suppress expression of the cellular isoform of GPx activity (Upchurch et al. 1997). The lower GPx activity in the present study with mink consuming the 17LNGB diet and the 67LNGB diet compared with mink consuming the SB diet is in agreement with the observations showing that cells treated with tHcy showed a significant decrease in GPx activity (Upchurch et al. 1997). 
Although there is a clear relationship between phospholipid intake and tHcy levels, it should be noted that the amounts of phospholipids from LNGB consumed during the present study were far from physiological, since the ordinary dietary intake of phospholipids is very low (Åkesson, 1982). The unfavourable effect of the very high level of PE on tHcy can be avoided by supplementation of folate that stimulates methionine synthase and thus tHcy removal (Mattson \& Haberman, 2003).

In conclusion, the lack of significant differences in the level of plasma PE due to the diets indicates that much of the PE in the LNGB diets was converted to $\mathrm{PC}$ in the liver. The results showed that the 67LNGB diet, rich in PE, caused higher levels of plasma tHcy and reduced PC than did the diet with soyabean oil as the major lipid source. Together with our previous study of the effects on plasma lipids, the results show that the phospholipid methylation from PE to PC is an important regulator of plasma lipoproteins and tHcy.

\section{Acknowledgements}

We gratefully acknowledge the Research Council of Norway for their financial support and Norferm AS for supplying the bacterial protein meal used for lipid extraction and Helene Kingsley-Smith for technical assistance at the research farm. Also, we thank Inger Johanne Jørgensen for her help with performing the GPx analyses and Lars Hellgren, for the previously analysed and published phospholipids analyses.

\section{References}

Agellon LB, Walkey CJ, Vance DE, Kuipers F \& Verkade HJ (1999) The unique acyl chain specificity of biliary phosphatidylcholines in mice is independent of their biosynthetic origin in the liver. Hepatology 30, $725-729$.

Åkesson B (1982) Content of phospholipids in human diets studied by the duplicate-portion technique. Br J Nutr 47, 223-229.

Bleich S, Carl M, Bayerlein K, Reulbach U, Biermann T, Hillemacher T, Bonsch D \& Kornhuber J (2005) Evidence of increased homocysteine levels in alcoholism: the Franconian alcoholism research studies (FARS). Alcohol Clin Exp Res 29, 334-336.

Bligh EG \& Dyer WJ (1959) A rapid method of total lipid extraction and purification. Can J Med Sci 37, 911-917.

Buchman AL, Dubin M, Jenden D, Moukarzel A, Roch MH, Rice K, Gornbein J, Ament ME \& Eckhert CD (1992) Lecithin increases plasma free choline and decreases hepatic steatosis in long-term total parenteral nutrition patients. Gastroenterol 102, 1363-1370.

Carrasco MP, Sanchez-Amate MC, Segovia JL \& Marco C (1996) Studies on phospholipid biosynthesis in hepatocytes from alcoholic rats by using radiolabeled exogenous precursors. Lipids 31, 393-397.

Chiang PK, Gordon RK, Tal J, Zeng GC, Doctor BP, Pardhasaradhi K \& McCann PP (1996) S-Adenosylmethionine and methylation. FASEB $J$ 10, 471-480.

Cui Z, Vance JE, Chen MH, Voelker DR \& Vance DE (1993) Cloning and expression of a novel phosphatidylethanolamine N-methyltransferase. A specific biochemical and cytological marker for a unique membrane fraction in rat liver. J Biol Chem 268, 16655-16663.

DeLong CJ, Hicks AM \& Cui Z (2002) Disruption of choline methyl group donation for phosphatidylethanolamine methylation in hepatocarcinoma cells. J Biol Chem 277, 17217-17225.

Finkelstein JD (1990) Methionine metabolism in mammals. J Nutr Biochem 1, 228-237.
Folch J, Lees M \& Stanley GHS (1957) A simple method for the isolation and purification of total lipides from animal tissues. J Biol Chem 226, 497-509.

Houweling M, Cui Z, Tessitore L \& Vance DE (1997) Induction of hepatocyte proliferation after partial hepatectomy is accompanied by a markedly reduced expression of phosphatidylethanolamine N-methyltransferase-2. Biochim Biophys Acta 1346, 1-9.

Kent C \& Carman GM (1999) Interactions among pathways for phosphatidylcholine metabolism, CTP synthesis and secretion through the Golgi apparatus. Trends Biochem Sci 24, 146-150.

Loehrer FM, Angst CP, Haefeli WE, Jordan PP, Ritz R \& Fowler B (1996) Low whole-blood S-adenosylmethionine and correlation between 5 methyltetrahydrofolate and homocysteine in coronary artery disease. Arterioscler Thromb Vasc Biol 16, 727-733.

McCleary BV, Solah V \& Gibson TS (1994) Quantitative measurements of total starch in cereal flours and products. J Cereal Sci 20, 51-58.

Makula RA (1978) Phospholipid composition of methane-utilizing bacteria. J Bacteriol 134, 771-777.

Martins PJ, Galdieri LC, Souza FG, Andersen ML, Benedito-Silva AA, Tufik S \& D'Almeida V (2005) Physiological variation in plasma total homocysteine concentrations in rats. Life Sci 76, 2621-2629.

Mattson MP \& Haberman F (2003) Folate and homocysteine metabolism: therapeutic targets in cardiovascular and neurodegenerative disorders. Curr Med Chem 10, 1923-1929.

Miller JW, Nadeau MR, Smith J, Smith D \& Selhub J (1994) Folatedeficiency-induced homocysteinaemia in rats: disruption of S-adenosylmethionine's co-ordinate regulation of homocysteine metabolism. Biochem J 298, 415-419.

Mudd SH, Finkelstein JD, Refsum H, et al. (2000) Homocysteine and its disulfide derivatives: a suggested consensus terminology. Arterioscler Thromb Vasc Biol 20, 1704-1706.

Müller H, Hellgren LI, Olsen E \& Skrede A (2004) Lipids rich in phosphatidylethanolamine from natural gas-utilizing bacteria reduce plasma cholesterol and classes of phospholipids: a comparison with soybean oil. Lipids 39, 833-841.

National Research Council (1982) Nutrient Requirements of Mink and Foxes, 2nd revised ed. Washington, DC: National Academy Press.

Noga AA, Stead LM, Zhao Y, Brosnan ME, Brosnan JT \& Vance DE (2003) Plasma homocysteine is regulated by phospholipid methylation. J Biol Chem 278, 5952-5959.

Noga AA \& Vance DE (2003) A gender-specific role for phosphatidylethanolamine $\mathrm{N}$-methyltransferase-derived phosphatidylcholine in the regulation of plasma high density and very low density lipoproteins in mice. J Biol Chem 278, 21851-21859.

Olthof MR \& Verhoef P (2005) Effects of betaine intake on plasma homocysteine concentrations and consequences for health. Curr Drug Metab 6, 15-22.

Paglia DE \& Valentine WN (1967) Studies on the quantitative and qualitative characteristics of the erythrocyte gluthatione peroxidase. $J \mathrm{Lab}$ Clin Med 70, 158-169.

Panagiotakos DB, Pitsaros C, Zampelas A, Zeimbekis A, Chyrsohoou C, Papademetriou L \& Stefanadis C (2004) The association between coffee consumption and plasma total homocysteine levels: the “ATTICA" study. Heart Vessels 19, 280-286.

Ridgway ND, Uao Z \& Vance DE (1989) Phosphatidylethanolamine levels and regulation of phosphatidylethanolamine N-methyltransferase. J Biol Chem 264, 1203-1207.

Rossi E, Beilby JP, McQuillan BM \& Hung J (1999) Biological variability and reference intervals for total plasma homocysteine. Ann Clin Biochem 36, 56-61.

Sehayek E, Wang R, Ono JG, Zinchuk VS, Duncan EM, Shefer S, Vance DE, Ananthanarayanan M, Chait BT \& Breslow JL (2003) Localization of the PE methylation pathway and SR-BI to the canalicular membrane: evidence for apical PC biosynthesis that may promote biliary excretion of phospholipid and cholesterol. J Lipid Res 44, 1605-1613.

Selhub J (1999) Homocysteine metabolism. Аnпи Rev Nutr 19, 217-246. 
Skrede A, Berge GM, Storebakken T, Herstad O, Aarstad K \& Sundstø1 F (1998) Digestibility of bacterial protein grown on natural gas in mink, pigs, chicken and Atlantic salmon. Anim Feed Sci Technol 76, 103-116.

Steenge GR, Verhoef P \& Katan MB (2003) Betaine supplementation lowers plasma homocysteine in healthy men and women. J Nutr 133, $1291-1295$.

Tijburg LB, Geelen MJH \& van Golde LMG (1989) Regulation of the biosynthesis of triacylglycerol, phosphatidylcholine and phosphatidylethanolamine in the liver. Biochem Biophys Acta 1004, 1-19.

Upchurch GR Jr, Welch GN, Fabian AJ, Freedman JE, Johnson JL, Keaney JF Jr \& Loscalzo J (1997) Homocyst(e)ine decreases bioavailable nitric oxide by a mechanism involving glutathione peroxidase. J Biol Chem 272, 17012-17017.

Verhoef P, Pasman WJ, van Vliet T, Urgert R \& Katan MB (2002) Contribution of caffeine to the homocysteine-raising effect of coffee: a randomized controlled trial in humans. Am J Clin Nutr 76, 1244-1248.

Wurtman RJ, Hirsch MJ \& Growdon JH (1979) Lecithin consumption raises serum-free-choline levels. Lancet ii, 68-69.

Yi P, Melnyk S, Pogribna M, Pogribny IP, Hine RJ \& James SJ (2000) Increase in plasma homocysteine associated with parallel increases in plasma S-adenosylhomocysteine and lymphocyte DNA hypomethylation. J Biol Chem 275, 29318-29323. 